\title{
Acute exercise induces biphasic increase in respiratory mRNA in skeletal muscle
}

Shin-ichi Ikeda ${ }^{1}$, Takako Kizaki ${ }^{2}$, Shukoh Haga $^{3}$, Hideki Ohno ${ }^{2}$ and Tohru Takemasa ${ }^{1}$

1: Graduate School of Comprehensive Human Sciences, University of Tsukuba, 1-1-1

Tennoudai, Tsukuba, Ibaraki 305-8574, Japan

2: Department of Molecular Predictive Medicine and Sport Science, Kyorin University,

School of Medicine, 6-20-2 Shinkawa, Mitaka, Tokyo 181-8611, Japan

3: Department of Exercise Physiology, Graduate School of Science, Tokyo Metropolitan

University, 1-1 Minami-Osawa, Hachioji, Tokyo 192-0397, Japan

Footnote: Mitochondria and p38 MAPK in skeletal muscle

Corresponding: Tohru Takemasa

Graduate School of Comprehensive Human Sciences, University of Tsukuba, 1-1-1 Tennoudai, Tsukuba, Ibaraki 305-8574, Japan

Tel Fax +81-29-853-2622

E-mail takemasa@taiiku.tsukuba.ac.jp 


\section{ABSTRACT}

Peroxisome proliferator-activated receptor $\gamma$ coactivator-1 $\alpha$ (PGC-1 $\alpha)$ promotes the expression of oxidative enzymes in skeletal muscle. We hypothesized that activation of the p38 MAPK (mitogen-activated protein kinase) in response to exercise was associated with exercise-induced PGC-1 $\alpha$ and respiratory enzymes expression and aimed to demonstrate this under the physiological level. We subjected mice to a single bout of treadmill running and found that the exercise induced a biphasic increase in the expression of respiratory enzymes mRNA. The second phase of the increase was accompanied by an increase in PGC-1 $\alpha$ protein, but the other was not. Administration of SB203580 (SB), an inhibitor of p38 MAPK, suppressed the increase in PGC-1 $\alpha$ expression and respiratory enzymes mRNA in both phases. These data suggest that $\mathrm{p} 38$ MAPK is associated with the exercise-induced expression of PGC-1 $\alpha$ and biphasic increase in respiratory enzyme mRNAs in mouse skeletal muscle under physiological conditions.

Key words: mitochondria, PGC-1 $\alpha$, p38 MAPK, single bout of exercise 


\section{INTRODUCTION}

Endurance exercise increases the expression of oxidative enzymes in the mitochondria of skeletal muscle [1]. However, the precise mechanism by which this increase occurs is obscure. PGC-1 $\alpha$, a transcriptional coactivator cloned from a differentiated brown fat cell line [2], has recently been shown to play an important role in adaptive thermogenesis, glucose metabolism, mitochondrial biogenesis and muscle fiber type specialization [3]. Several lines of evidence are consistent with the notion that PGC-1 $\alpha$ has a pivotal role in promoting oxidative capacity in skeletal muscle. Transient expression of the PGC-1 $\alpha$ gene induces an increase in mitochondrial gene expression in several cell lines $[2,4-6]$. Muscle-specific overexpression of PGC-1 $\alpha$ in transgenic mice results in enhanced mitochondrial biogenesis and slow-twitch (type I) fiber formation[7]. Although endurance exercise induces PGC-1 $\alpha$ mRNA and protein expression in rodents and humans [8-11], it is currently unknown whether exercise-induced PGC-1 $\alpha$ expression in skeletal muscle is essential for mitochondrial protein expression in physiological conditions because the notion that PGC-1 $\alpha$ induces mitochondrial protein expression was based on the findings of gain-of-function studies. 
The p38 mitogen activated protein kinase (MAPK) pathway in skeletal muscle has been a focus of recent study in myogenic cell differentiation, glucose metabolism and energy expenditure [12-14]. Although exercise induces activation of p38 MAPK in rodents and humans, the downstream effects of the activation in skeletal muscle are currently unknown. Based on several previous findings, we hypothesized that activation of $\mathrm{p} 38$ MAPK in response to exercise might mediate PGC-1 $\alpha$ expression, followed by expression of mitochondrial protein. For example, phosphorylated p38 MAPK can directly stimulate transcriptional factors of the PGC- $1 \alpha$ gene, such as ATF2 and MEF2 [15-17]. Overexpression of MKK3E, an upstream kinase of p38 MAPK, or wild-type p38 isoforms stimulates $\mathrm{PGC}-1 \alpha$ promoter activity in $\mathrm{C} 2 \mathrm{C} 12$ myocytes, whereas muscle-specific expression of MKK6E enhances PGC-1 $\alpha$ protein expression in fast-twitch muscles [18]. These data suggest that p38 MAPK is associated with exercise-induced PGC-1 $\alpha$ expression. However, it is uncertain whether activation of p38 MAPK stimulates PGC-1 $\alpha$ gene transcription, followed by mitochondrial enzyme expression under physiological conditions. This is because 1) previous studies merely showed that exercise induced phosphorylation of p38 MAPK, or 2) the results were based on methodology involving overexpression. 
In this study, we subjected mice to a single bout of treadmill running and investigated the effect of the exercise on expression of PGC-1 $\alpha$ and respiratory enzymes. Then, to determine the effect of p38 MAPK activation on the expression of PGC- $1 \alpha$ and respiratory enzymes under the physiological level, we used a pharmacological inhibitor of p38 MAPK, SB203580 (SB). We hypothesized that a single bout of exercise would induce expression of PGC-1 $\alpha$ and respiratory enzymes through activation of $\mathrm{p} 38$ MAPK in skeletal muscle, as shown in overexpression studies. 


\section{MATERIALS AND METHODS}

\section{Animals}

Female ICR mice (CLEA, Tokyo, Japan) aged 10 weeks were used. Food (Oriental Yeast, Tokyo, Japan) and water were provided ad libitum. The room temperature was maintained at $22 \pm 1{ }^{\circ} \mathrm{C}$ with a 12-h light (07:00 to 19:00) and 12-h dark (19:00 to 07:00) cycle. All protocols were approved by the Animal Experimental Committee of the University of Tsukuba.

\section{Exercise Protocols}

Mice were randomly assigned to either a non-exercised control group $(n=6)$ or exercise groups $(\mathrm{n}=36)$. Six days before the experiment, all of the mice were acclimated for three days to a motor-driven treadmill by walking at a speed of $5-10 \mathrm{~m} / \mathrm{min}$ for $15 \mathrm{~min}$ per day. Thirty-six mice then ran on the treadmill at $20 \mathrm{~m} / \mathrm{min}$ for $90 \mathrm{~min}$, and were anesthetized with an intraperitoneal injection of nembutal $(0.1 \mathrm{mg} / \mathrm{g}$ body weight $)$ immediately, or at $1,3,6,12$, or $24 \mathrm{~h}$ after exercise. Until anesthetization, food and water were provided ad libitum. Because the plantaris muscle is well recruited in treadmill running and has been used in several studies $[8,11,18,19]$, the muscle was dissected out quickly from each mouse, taking special care not to stretch it, frozen in 
liquid nitrogen, and stored at $-80^{\circ} \mathrm{C}$ until assay.

\section{SB203580 administration}

Forty-eight female ICR mice were divided into eight groups: control + saline, control + $\mathrm{SB}$, immediately after running + saline, immediately after running $+\mathrm{SB}, 1 \mathrm{~h}$ after running + saline, $1 \mathrm{~h}$ after running $+\mathrm{SB}, 12 \mathrm{~h}$ after running + saline and $12 \mathrm{~h}$ after running $+\mathrm{SB}$. Four groups of mice were administered SB dissolved in saline $(25 \mathrm{mg} / \mathrm{kg}$ body weight) twice by intraperitoneal injection, $16 \mathrm{~h}$ and $1 \mathrm{~h}$ before treadmill running, whereas the others were administered the same volume of saline. The dose of SB employed in a previously reported study was used [20], and we verified its effect before conducting the present study. After treatment with SB or saline, the mice were run on the treadmill at $20 \mathrm{~m} / \mathrm{min}$ for $90 \mathrm{~min}$, and then immediately after, $1 \mathrm{~h}$ or $12 \mathrm{~h}$ after running, they were killed, and their plantaris muscles were harvested, frozen in liquid nitrogen, and stored at $-80^{\circ} \mathrm{C}$ until assay. As all mice accomplished the exercise protocol, SB administration did not appear to affect running performance.

\section{RNA isolation}

Total RNA was extracted using the SV Total RNA Isolation System (Promega, WI, 
USA) according to the manufacturer's protocol. Total RNA concentration was determined spectrophotometrically at $260 \mathrm{~nm}$.

\section{Reverse transcription and real-time PCR}

First-strand cDNA was generated from $1 \mu \mathrm{g}$ of total RNA using ReverTra Ace $\alpha$ (TOYOBO, Osaka, Japan). Real-time PCR was performed using a 7500 Real Time PCR System (Applied Biosystems, CA, USA) and Power SYBR Green PCR Master Mix (Applied Biosystems). The PCR primers used were as: cyclophilin forward primer, 5'-CGATGACGAGCCCTTGG-3'; reverse, 5'-TCTGCTGTCTTTGGAACTTTGTC-3'; cytochrome $c$ (CYTC) forward primer, 5'- GCTTATCGGCCACCCAAGTG-3'; reverse, 5'-GGGCTGCTGAGAGCTTGTTC-3'; cytochrome $c$ oxidase subunit IV (COXIV) forward primer, 5'-TACTTCGGTGTGCCTTCGA-3'; $\quad$ reverse, 5'-TGACATGGGCCACATCAG-3'; ATP synthase $\beta$ subunit (ATPsyn $\beta$ ) forward primer, 5'- CAGGCTATCTATGTGCCTGCTGAT-3'; reverse, 5'-GCATCCAAATGGGCAAAGG-3', carnitine palmitoyltransferase I (CPT-I) forward primer, 5'-ACCACATCCGCCAAGCA-3'; reverse, 5'-TTCCTCAGCTGTCTGTCTTGGA-3'. The PCR conditions for all genes consisted of one denaturing cycle at $95^{\circ} \mathrm{C}$ for $10 \mathrm{~min}, 40$ cycles consisting of denaturing at $95^{\circ} \mathrm{C}$ for 
$15 \mathrm{~s}$, and annealing and elongation at $60^{\circ} \mathrm{C}$ for $1 \mathrm{~min}$. At the end of the PCR, the samples were subjected to dissociation curve analyses. The relative amounts of mRNA were determined by the standard curve method. Signals were normalized against cyclophilin mRNA. We also used S26 ribosomal protein as an internal control and this provided results similar to those when the PCR signals were normalized to cyclophilin. Cyclophilin and S26 mRNAs were not affected by either exercise or SB203580 (data not shown). All samples for each gene were run in duplicate.

\section{Western blotting}

For PGC-1 $\alpha$ protein analysis, dissected plantaris muscles were homogenized and analyzed as described previously [19].

\section{Protein kinase assay for $\mathbf{p} 38$ MAPK}

p38 MAPK kinase activity was determined as described previously with some modifications [16]. In brief, in vitro kinase assays were performed at $37{ }^{\circ} \mathrm{C}$ for $30 \mathrm{~min}$ by using $10 \mu \mathrm{l}$ of whole-muscle lysates, $2 \mu \mathrm{g}$ of substrate ATF-2 Fusion Protein (purchased from Cell Signaling) and $250 \mu \mathrm{M}$ ATP in $40 \mu \mathrm{l}$ kinase reaction buffer. The ATF-2 fragment used in these experiments was a specific substrate for p38 MAPK [21]. 
An equivalent amount of $2 \times$ Laemmli sample buffer was added to terminate the reactions. Proteins were resolved with $10 \%$ polyacrylamide gels, transfered to PVDF membrane, and detected by anti phospho-ATF-2 antibodies (Cell Signaling). The level of p38 MAPK in the cell lysates was detected by Western blotting with antibodies against p38 MAPK.

\section{Statistical analysis}

All data are expressed as means \pm SE. The effect of treadmill running was analyzed using one-way ANOVA. Two-way ANOVA was used for SB203580 administration studies. If ANOVA indicated a significant difference, Tukey HSD was performed to determine the significance of the difference between means. 


\section{RESULTS AND DISCUSSION}

\section{Effect of a single bout of exercise on PGC-1 $\alpha$ protein and respiratory enzyme}

\section{mRNAs expression in mitochondria of mouse skeletal muscle}

A 90-min bout of treadmill running induced transient PGC-1 $\alpha$ protein expression 6 to $12 \mathrm{~h}$ after exercise, with an about 1.5 -fold increase $(\mathrm{p}<0.05$ compared to pre group, Fig. 1A). This increase in PGC-1 $\alpha$ expression returned to control levels within $24 \mathrm{~h}$ after exercise. The kinetics of the increase in PGC- $1 \alpha$ protein is comparable to those in previous studies of human and rat muscle $[9,10]$.

Recent studies have indicated that PGC-1 $\alpha$ has a pivotal role in mitochondrial biogenesis and that PGC-1 $\alpha$ expression is a rate-limiting step for mitochondrial gene expression in skeletal muscle $[10,18,22-24]$. Therefore, we investigated temporal changes in the expression of respiratory enzyme (CYTC, COXIV and ATPsyn $\beta$ ) mRNAs in mouse skeletal muscle after a single 90 -min bout of treadmill running. The exercise induced a biphasic increase in the expression of respiratory enzyme mRNAs in the plantaris muscle (Fig. 1B). The second phase increase $(6 \sim 12 \mathrm{~h}$ after exercise) in respiratory enzyme mRNA expression was concomitant with an increase in PGC-1 $\alpha$ protein expression level, but the first phase increase (1 h after exercise) showed slightly 
but no such a clear correlation. These data suggested that skeletal muscle have another way to induce the expression of respiratory enzymes rather than PGC $1 \alpha$ expression in 1st phase.

It is surprising that a single bout of exercise induced a biphasic increase in the expression of respiratory enzyme mRNAs. Hildebrandt et al. and Pilegaard et al. reported that exercise stimulated the transcription of several genes expressed in mitochondria including pyruvate dehydrogenase kinase-4 (PDK4), uncoupling protein-3 (UCP3) and CPT-I in rat and human, respectively [9, 25]. However, these increases were not biphasic. To assess whether the biphasic increase after single bout of exercise is specific for respiratory enzyme mRNAs, we measured the mRNA expression of CPT-I after single bout of exercise. As shown in Fig 1B, CPT-I mRNA was increased 6 and $12 \mathrm{~h}$ after single bout of exercise (1.8-fold increase after $6 \mathrm{~h}$ and 1.7 -fold increase after $12 \mathrm{~h}$ ). The kinetics of CPT-I mRNA increase is transient as shown in previous studies $[9,25]$. These results suggested that biphasic increase is specific to respiratory enzymes. The difference in post-exercise mitochondrial enzyme expression between the respiratory and CPT-I mRNAs might be explained for by differences in the transcriptional regulator involved. Several previous studies have suggested that transcription of respiratory enzymes is regulated by transcription factors such as, 
Nuclear Respiratory Factor-1 and -2 (NRF-1 and 2) or Estrogen-related Receptor $\alpha$ [26, 27]. On the other hand, it has been considered that expression of PDK4, UCP3 and CPT-I is modulated by members of the peroxisome proliferators-activated receptor family [28-30].

Effect of inhibition of p38 MAPK activation in response to a single bout of exercise on expression of PGC-1 $\alpha$ and respiratory enzymes

Many previous reports have demonstrated that exercise or contraction activates MAPK signaling [21, 31-35], and that MAPK activity increases immediately after an acute bout of exercise [21,34] or electrical stimulation [35]. We speculated that MAPK, especially p38, mediates increases in PGC-1 $\alpha$ expression and respiratory mRNA after acute treadmill running. Therefore, we assessed temporal changes in p38 MAPK activity after acute treadmill running by kinase assay using ATF-2 Fusion Protein as a specific substrate of p38 MAPK in mouse skeletal muscles. Activity of p38 MAPK was increased $0 \mathrm{~h}$ after treadmill running and returned to the base level after $12 \mathrm{~h}$ (Fig. 2A).

To determine whether p38 MAPK activation is required for induction of the PGC-1 $\alpha$ and respiratory enzyme gene after treadmill running, mice were pretreated with SB, a pharmacological inhibitor of p38 MAPK, and then expression levels of 
PGC- $1 \alpha$ and respiratory enzyme mRNAs in the plantaris muscle were determined after treadmill exercise. As shown in Fig. 2A, p38 MAPK activity in the plantaris muscle was increased $0 \mathrm{~h}$ after cessation of treadmill running and this increase was inhibited about $50 \%$ by pretreatment with SB. This is the first report that can inhibit exercise-induced activation of $\mathrm{p} 38 \mathrm{MAPK}$ in skeletal muscle in vivo. Administration of SB also suppressed the exercise-related induction of PGC-1 $\alpha$ protein expression completely in the plantaris muscle (12 $\mathrm{h}$ after exercise, Fig $2 \mathrm{~B})$. This result suggested that exercise-induced increase in PGC-1 $\alpha$ expression required for $\mathrm{p} 38$ MAPK activation. As stated above, acute exercise induced a biphasic increase in the expression of respiratory enzyme mRNAs. The first phase was not concomitant with PGC-1 $\alpha$ protein expression, whereas the second phase ( 6 and $12 \mathrm{~h}$ after exercise) was accompanied by an increase in PGC-1 $\alpha$ protein. Administration of SB also suppressed both phase increase in respiratory mRNA (Fig 3). These finding suggest that p38 MAPK is a central mediator of exercise-induced respiratory enzyme expression in skeletal muscle. However, how does p38 MAPK mediate the expression of respiratory enzyme mRNAs in both phases of the increase? In the second phase, SB was able to inhibit the exercise-induced increase in PGC-1 $\alpha$ protein. Therefore, it can be thought that p38 MAPK mediates the expression of respiratory enzyme mRNAs in the second phase through induction of 
PGC-1 $\alpha$ expression. On the other hand, it is more difficult to account for the first phase of the increase. One possibility is phosphorylation of PGC-1 $\alpha$ by p38 MAPK. p38 MAPK phosphorylates PGC-1 $\alpha$ at three residues (T262, S265 and T298), and this increases the stability and half-life of the molecule [12]. Another study has demonstrated that p160 myb binding protein (p160MBP) binds this region (amino acids 200-403) and represses the activity of PGC-1 $\alpha$ as a transcriptional coactivator. When phosphorylated in this region, p160MBP dissociates from PGC-1 $\alpha$, and PGC-1 $\alpha$ becomes able to bind transcriptional factors such as NRF-1 and initiate transcriptional activity $[36,37]$. NRF-1 is an important transcription factor regulating the expression of mitochondrial enzymes [38, 39]. Currently, it is unknown whether exercise induces phosphorylation of PGC- $1 \alpha$ via p38 MAPK pathways, and this issue will require future study. 


\section{ACKNOWLEDGMENT}

This work was supported in part by Grants \#15200048 and \#17650189 and in part by the Nishihira/Tsukuba Project of the 21st Century of COE (Center of Excellence) program from Ministry of Education, Culture, Sports, Science and Technology. 


\section{REFERENCES}

[1] J.O. Holloszy, F.W. Booth, Biochemical adaptations to endurance exercise in muscle, Annu Rev Physiol 38 (1976) 273-291.

[2] P. Puigserver, Z. Wu, C.W. Park, R. Graves, M. Wright, B.M. Spiegelman, A cold-inducible coactivator of nuclear receptors linked to adaptive thermogenesis, Cell $92(1998) 829-839$.

[3] D. Knutti, A. Kralli, PGC-1, a versatile coactivator, Trends Endocrinol Metab 12 (2001) 360-365.

[4] Z. Wu, P. Puigserver, U. Andersson, C. Zhang, G. Adelmant, V. Mootha, A. Troy, S.

Cinti, B. Lowell, R.C. Scarpulla, B.M. Spiegelman, Mechanisms controlling mitochondrial biogenesis and respiration through the thermogenic coactivator PGC-1, Cell 98 (1999) 115-124.

[5] J.J. Lehman, P.M. Barger, A. Kovacs, J.E. Saffitz, D.M. Medeiros, D.P. Kelly, Peroxisome proliferator-activated receptor gamma coactivator-1 promotes cardiac mitochondrial biogenesis, J Clin Invest 106 (2000) 847-856.

[6] J.C. Yoon, P. Puigserver, G. Chen, J. Donovan, Z. Wu, J. Rhee, G. Adelmant, J.

Stafford, C.R. Kahn, D.K. Granner, C.B. Newgard, B.M. Spiegelman, Control of 
hepatic gluconeogenesis through the transcriptional coactivator PGC-1, Nature 413 (2001) 131-138.

[7] Y.T. Kruszynska, D.S. Worrall, J. Ofrecio, J.P. Frias, G. Macaraeg, J.M. Olefsky, Fatty acid-induced insulin resistance: decreased muscle PI3K activation but unchanged Akt phosphorylation, J Clin Endocrinol Metab 87 (2002) 226-234.

[8] S. Terada, I. Tabata, Effects of acute bouts of running and swimming exercise on PGC-1alpha protein expression in rat epitrochlearis and soleus muscle, Am J Physiol Endocrinol Metab 286 (2004) E208-216.

[9] A.L. Hildebrandt, H. Pilegaard, P.D. Neufer, Differential transcriptional activation of select metabolic genes in response to variations in exercise intensity and duration, Am J Physiol Endocrinol Metab 285 (2003) E1021-1027.

[10] K. Baar, A.R. Wende, T.E. Jones, M. Marison, L.A. Nolte, M. Chen, D.P. Kelly, J.O. Holloszy, Adaptations of skeletal muscle to exercise: rapid increase in the transcriptional coactivator PGC-1, Faseb J 16 (2002) 1879-1886.

[11] T. Akimoto, T.J. Ribar, R.S. Williams, Z. Yan, Skeletal muscle adaptation in response to voluntary running in $\mathrm{Ca} 2+/$ calmodulin-dependent protein kinase IV-deficient mice, Am J Physiol Cell Physiol 287 (2004) C1311-1319.

[12] P. Puigserver, J. Rhee, J. Lin, Z. Wu, J.C. Yoon, C.Y. Zhang, S. Krauss, V.K. 
Mootha, B.B. Lowell, B.M. Spiegelman, Cytokine stimulation of energy expenditure through p38 MAP kinase activation of PPARgamma coactivator-1, Mol Cell 8 (2001) 971-982.

[13] M. Sano, Y. Izumi, K. Helenius, M. Asakura, D.J. Rossi, M. Xie, G. Taffet, L. Hu, R.G. Pautler, C.R. Wilson, S. Boudina, E.D. Abel, H. Taegtmeyer, F. Scaglia, B.H. Graham, A. Kralli, N. Shimizu, H. Tanaka, T.P. Makela, M.D. Schneider, Menage-a-Trois 1 Is Critical for the Transcriptional Function of PPARgamma Coactivator 1, Cell Metab 5 (2007) 129-142.

[14] A. Zetser, E. Gredinger, E. Bengal, p38 mitogen-activated protein kinase pathway promotes skeletal muscle differentiation. Participation of the Mef2c transcription factor, J Biol Chem 274 (1999) 5193-5200.

[15] C. Handschin, J. Rhee, J. Lin, P.T. Tarr, B.M. Spiegelman, An autoregulatory loop controls peroxisome proliferator-activated receptor gamma coactivator 1alpha expression in muscle, Proc Natl Acad Sci U S A 100 (2003) 7111-7116.

[16] W. Cao, K.W. Daniel, J. Robidoux, P. Puigserver, A.V. Medvedev, X. Bai, L.M. Floering, B.M. Spiegelman, S. Collins, p38 mitogen-activated protein kinase is the central regulator of cyclic AMP-dependent transcription of the brown fat uncoupling protein 1 gene, Mol Cell Biol 24 (2004) 3057-3067. 
[17] M. Zhao, L. New, V.V. Kravchenko, Y. Kato, H. Gram, F. di Padova, E.N. Olson, R.J. Ulevitch, J. Han, Regulation of the MEF2 family of transcription factors by p38, Mol Cell Biol 19 (1999) 21-30.

[18] T. Akimoto, S.C. Pohnert, P. Li, M. Zhang, C. Gumbs, P.B. Rosenberg, R.S. Williams, Z. Yan, Exercise stimulates Pgc-1alpha transcription in skeletal muscle through activation of the p38 MAPK pathway, J Biol Chem 280 (2005) 19587-19593.

[19] S. Ikeda, H. Kawamoto, K. Kasaoka, Y. Hitomi, T. Kizaki, Y. Sankai, H. Ohno, S. Haga, T. Takemasa, Muscle type-specific response of PGC-1alpha and oxidative enzymes during voluntary wheel running in mouse skeletal muscle, Acta Physiol (Oxf) 188 (2006) 217-223.

[20] A.M. Badger, J.N. Bradbeer, B. Votta, J.C. Lee, J.L. Adams, D.E. Griswold, Pharmacological profile of SB 203580, a selective inhibitor of cytokine suppressive binding protein/p38 kinase, in animal models of arthritis, bone resorption, endotoxin shock and immune function, J Pharmacol Exp Ther 279 (1996) 1453-1461.

[21] L.J. Goodyear, P.Y. Chang, D.J. Sherwood, S.D. Dufresne, D.E. Moller, Effects of exercise and insulin on mitogen-activated protein kinase signaling pathways in rat skeletal muscle, Am J Physiol 271 (1996) E403-408.

[22] S. Terada, M. Goto, M. Kato, K. Kawanaka, T. Shimokawa, I. Tabata, Effects of 
low-intensity prolonged exercise on PGC-1 mRNA expression in rat epitrochlearis muscle, Biochem Biophys Res Commun 296 (2002) 350-354.

[23] M. Goto, S. Terada, M. Kato, M. Katoh, T. Yokozeki, I. Tabata, T. Shimokawa, cDNA Cloning and mRNA analysis of PGC-1 in epitrochlearis muscle in swimming-exercised rats, Biochem Biophys Res Commun 274 (2000) 350-354.

[24] I. Irrcher, P.J. Adhihetty, T. Sheehan, A.M. Joseph, D.A. Hood, PPARgamma coactivator-1alpha expression during thyroid hormone- and contractile activity-induced mitochondrial adaptations, Am J Physiol Cell Physiol 284 (2003) C1669-1677.

[25] H. Pilegaard, G.A. Ordway, B. Saltin, P.D. Neufer, Transcriptional regulation of gene expression in human skeletal muscle during recovery from exercise, Am J Physiol Endocrinol Metab 279 (2000) E806-814.

[26] R.C. Scarpulla, Transcriptional activators and coactivators in the nuclear control of mitochondrial function in mammalian cells, Gene 286 (2002) 81-89.

[27] S.N. Schreiber, R. Emter, M.B. Hock, D. Knutti, J. Cardenas, M. Podvinec, E.J. Oakeley, A. Kralli, The estrogen-related receptor alpha (ERRalpha) functions in PPARgamma coactivator 1alpha (PGC-1alpha)-induced mitochondrial biogenesis, Proc Natl Acad Sci U S A 101 (2004) 6472-6477.

[28] Y.X. Wang, C.H. Lee, S. Tiep, R.T. Yu, J. Ham, H. Kang, R.M. Evans, 
Peroxisome-proliferator-activated receptor delta activates fat metabolism to prevent obesity, Cell 113 (2003) 159-170.

[29] Y. Kamei, H. Ohizumi, Y. Fujitani, T. Nemoto, T. Tanaka, N. Takahashi, T. Kawada, M. Miyoshi, O. Ezaki, A. Kakizuka, PPARgamma coactivator 1beta/ERR ligand 1 is an ERR protein ligand, whose expression induces a high-energy expenditure and antagonizes obesity, Proc Natl Acad Sci U S A 100 (2003) 12378-12383.

[30] T. Teruel, S.A. Smith, J. Peterson, J.C. Clapham, Synergistic activation of UCP-3 expression in cultured fetal rat brown adipocytes by PPARalpha and PPARgamma ligands, Biochem Biophys Res Commun 273 (2000) 560-564.

[31] T. Hayashi, M.F. Hirshman, S.D. Dufresne, L.J. Goodyear, Skeletal muscle contractile activity in vitro stimulates mitogen-activated protein kinase signaling, Am J Physiol 277 (1999) C701-707.

[32] J.S. Lee, C.R. Bruce, B.E. Spurrell, J.A. Hawley, Effect of training on activation of extracellular signal-regulated kinase $1 / 2$ and p38 mitogen-activated protein kinase pathways in rat soleus muscle, Clin Exp Pharmacol Physiol 29 (2002) 655-660.

[33] D. Aronson, S.D. Dufresne, L.J. Goodyear, Contractile activity stimulates the c-Jun NH2-terminal kinase pathway in rat skeletal muscle, J Biol Chem 272 (1997) 25636-25640. 
[34] U. Widegren, X.J. Jiang, A. Krook, A.V. Chibalin, M. Bjornholm, M. Tally, R.A.

Roth, J. Henriksson, H. Wallberg-henriksson, J.R. Zierath, Divergent effects of exercise on metabolic and mitogenic signaling pathways in human skeletal muscle, Faseb J 12 (1998) 1379-1389.

[35] D.J. Sherwood, S.D. Dufresne, J.F. Markuns, B. Cheatham, D.E. Moller, D. Aronson, L.J. Goodyear, Differential regulation of MAP kinase, p70(S6K), and Akt by contraction and insulin in rat skeletal muscle, Am J Physiol 276 (1999) E870-878.

[36] P. Puigserver, G. Adelmant, Z. Wu, M. Fan, J. Xu, B. O'Malley, B.M. Spiegelman, Activation of PPARgamma coactivator-1 through transcription factor docking, Science 286 (1999) 1368-1371.

[37] M. Fan, J. Rhee, J. St-Pierre, C. Handschin, P. Puigserver, J. Lin, S. Jaeger, H. Erdjument-Bromage, P. Tempst, B.M. Spiegelman, Suppression of mitochondrial respiration through recruitment of p160 myb binding protein to PGC-1alpha: modulation by p38 MAPK, Genes Dev 18 (2004) 278-289.

[38] J.V. Virbasius, R.C. Scarpulla, Activation of the human mitochondrial transcription factor A gene by nuclear respiratory factors: a potential regulatory link between nuclear and mitochondrial gene expression in organelle biogenesis, Proc Natl Acad Sci U S A 91 (1994) 1309-1313. 
[39] M.J. Evans, R.C. Scarpulla, NRF-1: a trans-activator of nuclear-encoded respiratory genes in animal cells, Genes Dev 4 (1990) 1023-1034. 


\section{FIGURE LEGENDS}

\section{Figure 1}

Effect of a single bout of exercise on PGC-1 $\alpha$ protein expression (A) and mitochondrial mRNA expression (B). The pre group was assigned a value of 1.0; all other values are expressed relative to this value. All values are reported as means $\pm \operatorname{SE}(n=6)$. * significantly different from the pre group $(\mathrm{p}<0.05)$.

\section{Figure 2}

Administration of $25 \mathrm{mg} / \mathrm{kg}$ SB203580 inhibits exercise-induced activation of p38 MAPK and PGC-1 $\alpha$ expression in mouse skeletal muscle. (A) p38 MAPK kinase assay and (B) Western blotting using anti-PGC1 antibody. All values are reported as means $\pm \mathrm{SE}(\mathrm{n}=6) .{ }^{*}$ significantly different from the control + saline group, \# significantly different from the $12 \mathrm{~h}+$ saline group $(\mathrm{p}<0.01)$.

\section{Figure 3}

Expression of mRNAs for CYTC, COXIV and ATPsyn $\beta$ in mouse plantaris muscle. All values are reported as means $\pm \mathrm{SE}(\mathrm{n}=6) .{ }^{*}$ significantly different from the control + saline group, \# significantly different from the $1 \mathrm{~h}+$ saline group, $\$$ significantly different from the $12 \mathrm{~h}+$ saline group $(\mathrm{p}<0.05)$. 
Fig. 1

A.

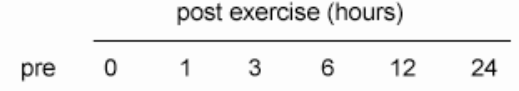

PGC- $1 \alpha$

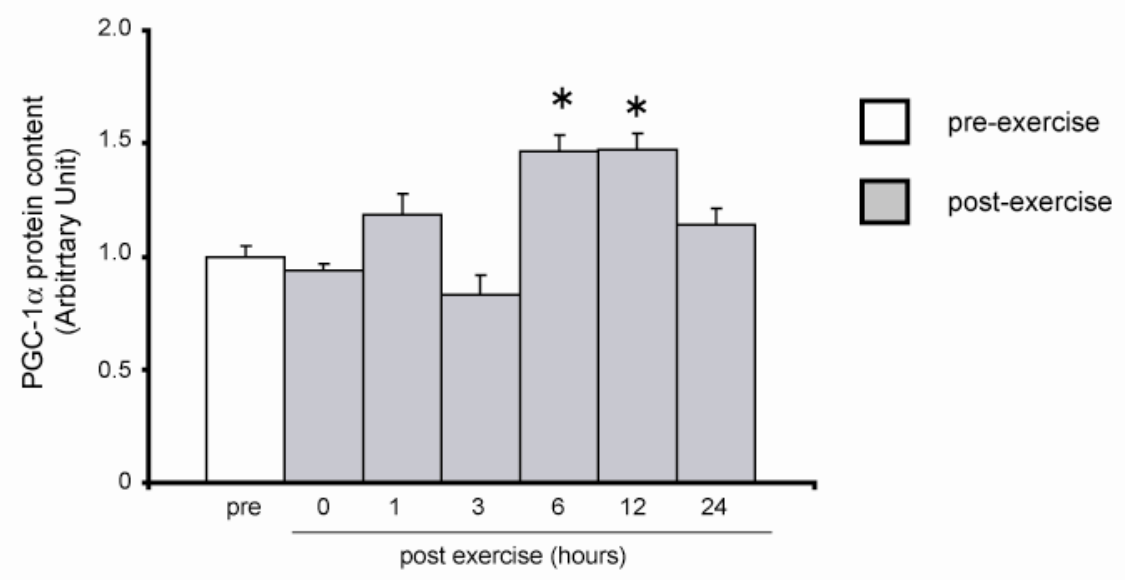

B.

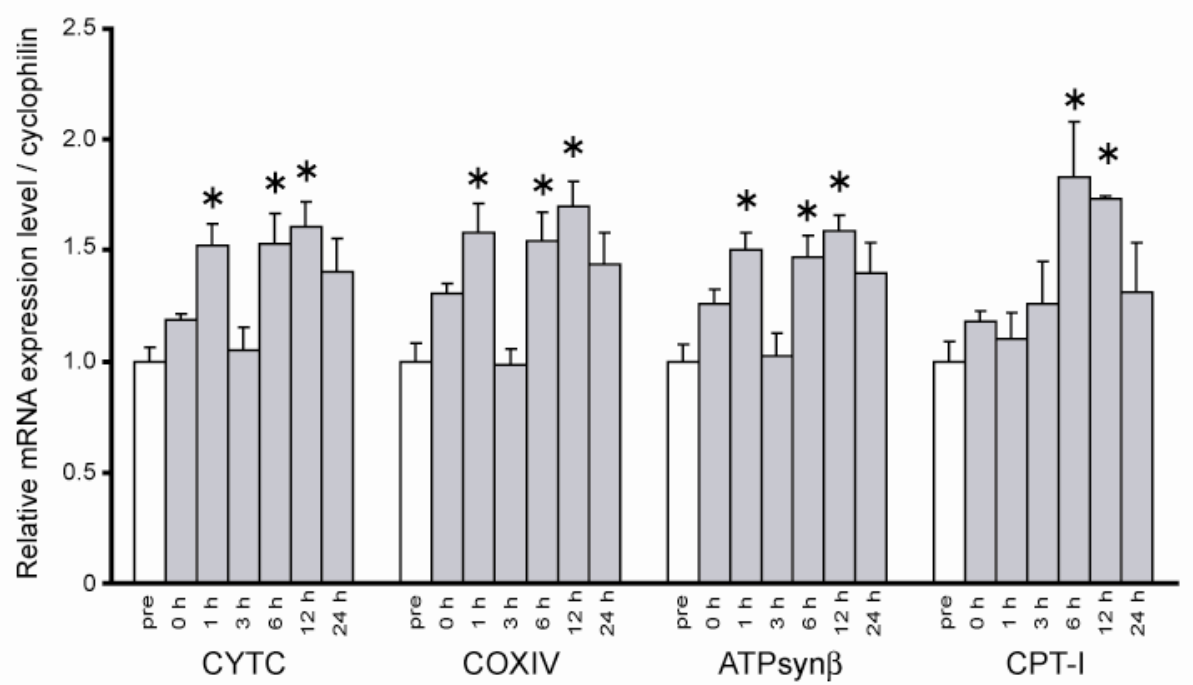


Fig. 2

A.

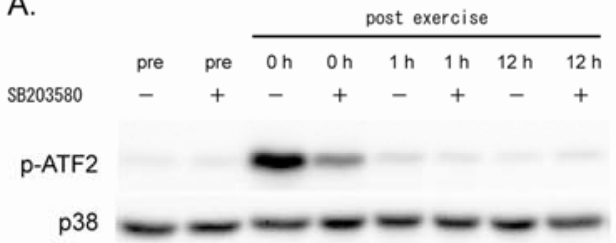

p3

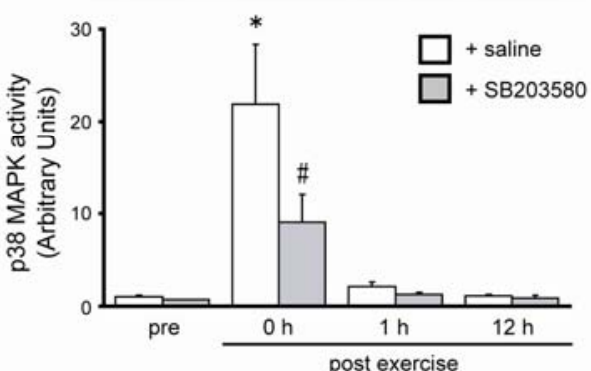

B.
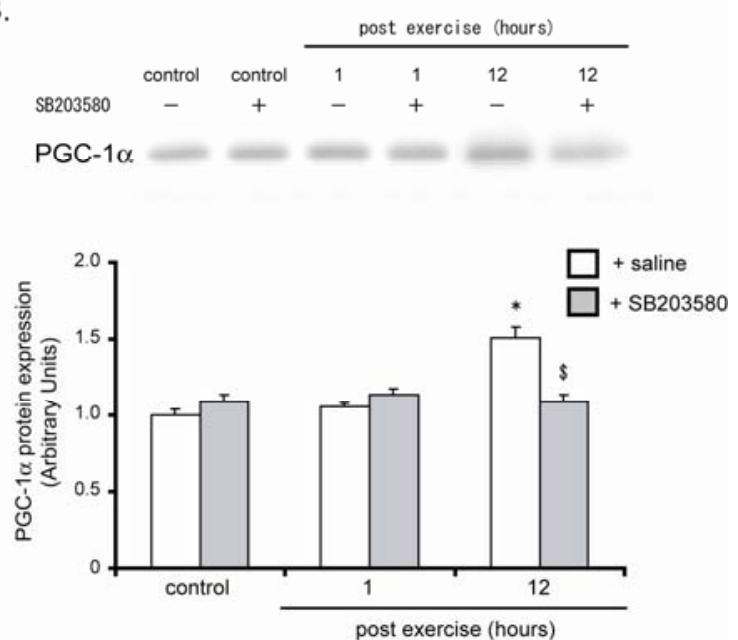
Fig. 3
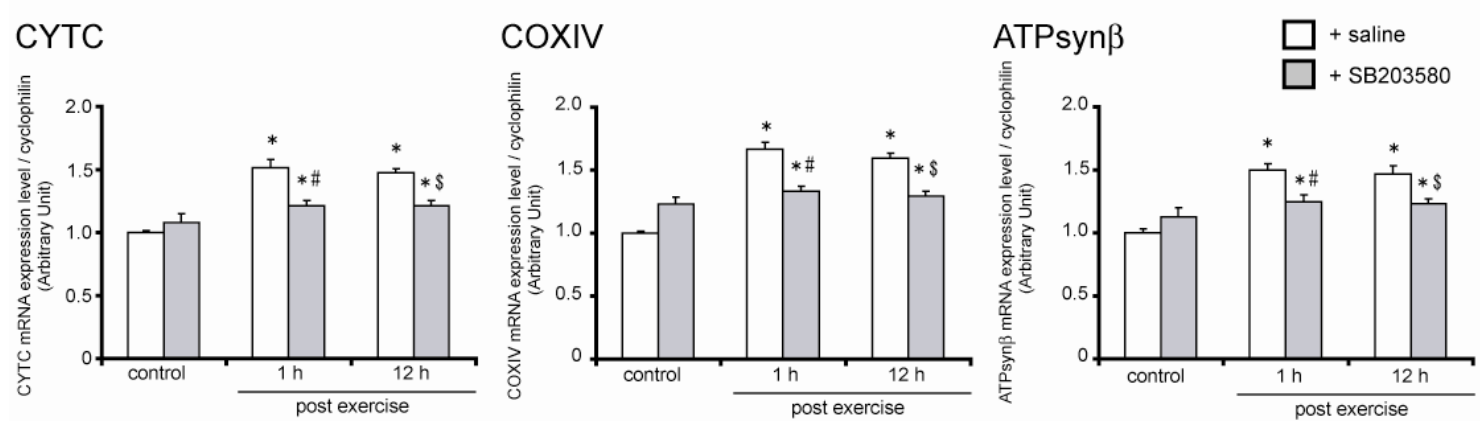